\title{
Descrição macroscópica da musculatura dos membros do Tupinambis merianae
}

\author{
Juliana Barbosa Casals ${ }^{1 *}$ \\ Naira Caroline Pieri Godoy ${ }^{1}$ \\ Fabio Sergio Cury ${ }^{2}$ \\ Lindsay Baltel Paskoski \\ Moacir Franco de Oliveira ${ }^{3}$ \\ Daniele dos Santos Martins ${ }^{1,2}$ \\ Laís Vicari de Figueiredo Pessôa ${ }^{1}$ \\ Maria Angélica Miglino ${ }^{1}$ \\ Carlos Eduardo Ambrósio ${ }^{1,2 *}$
}

\begin{abstract}
${ }^{1}$ Faculdade de Medicina Veterinária e Zootecnia, Universidade de São Paulo Av. Prof. Dr. Orlando Marques de Paiva, 87, CEP 05508-270, São Paulo - SP, Brasil

${ }^{2}$ Faculdade de Zootecnia e Engenharia de Alimentos, Universidade de São Paulo Av. Duque de Caxias Norte, CEP 13635-000, Pirassununga - SP, Brasil ${ }^{3}$ Departamento de Ciência Animal, Universidade Federal Rural do Semi-Árido Av. Francisco Mota, CEP 59625-900, Mossoró - RN, Brasil

*Autores para correspondência julianacasals@usp.br ceambrosio@usp.br
\end{abstract}

Submetido em 18/05/2011

Aceito para publicação em 10/10/2011

\section{Resumo}

O lagarto teiú (Tupinambis merianae) pertence à família Teiidae. Distribui-se ao longo das Américas, com numerosas espécies, inclusive no Brasil. São do gênero Tupinambis, os maiores representantes da família Teiidae. Para este estudo foram utilizados três animais (atropelados) provenientes de doação. Os lagartos dissecados foram fixados em formol 10\%, e a análise macroscópica foi realizada de forma detalhada e fotodocumentada, guardando as estruturas selecionadas "in situ". Este trabalho teve como principal objetivo contribuir com a descrição macroscópica da miologia peitoral e dos membros torácico e pélvico do lagarto T. merianae. Os resultados obtidos nesta pesquisa foram comparados com autores que estudaram animais da mesma classe Reptilia. Com isso, concluímos que nossos resultados macroscópicos assemelham-se aos já descritos pelos pesquisadores Hildebrand (1995), Moro e Abdala, (2004) e Abdala e Diogo (2010). Devemos ressaltar que o conhecimento da anatomia tem importâncias e aplicações em diversas áreas dentro da Biologia, contribuindo de maneira substancial para as áreas da saúde humana e da tecnologia.

Palavras-chave: Lagarto, Répteis, Teiidae, Teiú 


\section{Abstract}

Macroscopic description of the limb muscles of Tupinambis merianae. Tegu lizard (Tupinambis merianae) belongs to the Teiidae family. It is distributed throughout the Americas, with many species, including Brazilian ones. They are from the Tupinambis genus, the largest representatives of the Teiidae family. For this study three animals (run over) coming from donation were used. The dissected lizards were fixed in $10 \%$, formaldehyde, and the macroscopic analysis was carried out in a detailed and photo documented way, keeping the selected structures "in situ". This paper had as its main aim contributing to the macroscopic description of the chest myology, as well as the thoracic and pelvic limbs of the lizard T. merianae. The results obtained from this research were compared to authors who have studied animals from the same Reptilia class. Thus, we conclude that our macroscopic results are similar to those already described by the researchers Hildebrand (1995), Moro and Abdala (2004) and Abdala and Diogo (2010). We should highlight that the knowledge on anatomy has importance and applications to various areas within Biology, contributing in a substantial way to the areas of human health and technology.

Key words: Lizard, Reptiles, Tegu, Teiidae

\section{Introdução}

O lagarto teiú (Tupinambis merianae) é conhecido popularmente como tiú, tejú ou tegú. É um réptil do grupo Squamata, do gênero Tupinambis, que além dos lagartos, inclui os anfisbênios e as serpentes. Pertence à família Teiidae, que se distribui ao longo das Américas, com sete espécies (T. longilineus; T. duseni; T. rufescens; T. palustres; T. quadrilineatus; T. teguixin e T. merianae), sendo as duas últimas amplamente representadas. Estas duas são semelhantes morfologicamente e por serem simpátricas em algumas regiões brasileiras, ocasionam equívocos quanto à sua classificação (FARIA, 2005). São, juntamente com os jacuruxis (Dracaena sp.), os maiores representantes da família Teiidae (PÉRES JR., 2003).

Dentro do gênero a espécie T. merianae apresenta a maior distribuição, abrangendo do sul da Amazônia ao norte da Patagônia e leste dos Andes (WINCK, 2007). $\mathrm{Na}$ literatura existem divergências quanto à variedade de espécies e gêneros da família Teiidae. Pérez Jr. (2003), diz existirem mais de 100 espécies já descritas, sendo que 30 delas ocorrem no Brasil, enquanto Francisco (1997) e Silva e Costa (2005), dizem existirem mais de 200 espécies e aproximadamente 40 gêneros.

A espécie possui corpo cilíndrico e robusto, podendo atingir até $1,4 \mathrm{~ms}$ de comprimento e cerca de $5 \mathrm{~kg}$. A cabeça é comprida e pontiaguda, delimitada por um sulco, que liga a entrada do ouvido e o pescoço largo
(ÁVILA-PIRES, 1995), a mandíbula é forte e provida de um grande número de pequenos dentes pontiagudos, a língua cor-de-rosa, comprida e bífida e a cauda longa e musculosa. Quando adulto possui coloração negra, com manchas presentes na região dorsal do corpo, cabeça e membros que podem variar da coloração amarelada até branca. Já o ventre é branco com pequenas manchas negras mais claras e, quando filhote, apresenta coloração esverdeada (FRANCISCO, 1997; SILVA e COSTA, 2005; COSTA e MOURA, 2009).

Os Teiús buscam seus alimentos ativamente no chão, com o auxílio da língua bífida, que capta partículas de cheiro do ar (CASTRO; GALETTI, 2004). A dieta destes animais é muito variada, comem praticamente de tudo: ovos, frutas, larvas, vermes, artrópodes e até pequenos vertebrados. São importantes dispersores de sementes uma vez que se deslocam por grandes áreas em busca de comida (COLLI, 2005).

São animais de hábito diurno que se expõem ao sol para elevar a temperatura corporal, e nos meses frios, permanecem entocados e inativos por um longo período (CASTRO; GALETTI, 2004).

Aves de rapina, felinos selvagens e serpentes são alguns dos predadores dos teiús na natureza. Em cativeiro, esta espécie pode viver mais de 15 anos (MAFFEI et al., 2007).

Quanto à reprodução, os teiús são ovíparos, têm ninhadas com média de 13 a 35 ovos que são incubados 
por 60 a 90 dias e atingem maturidade sexual com aproximadamente três anos de idade (FARIA, 2005).

Estudos recentes com a espécie foram desenvolvidos por Haddad Jr. et al. (2008), que descrevem os danos causados por mordedura de teiús em seres humanos, e Argôlo Filho (2007) estudou a identificação, sorotipagem e diferenciação por PCR-DGGE de sorotipos de Salmonela em teiús criados em cativeiros. Maffei et al. (2007) analisou a genética e hematologia de lagartos do gênero Tupinambis, Castro e Galetti (2004) estudaram a frugivoria e a dispersão de sementes destes lagartos em cativeiro.

Silva e Costa (2004) descreveram as observações da corte e cópula de Tupinambis e, posteriormente, pesquisaram sobre os padrões motores desta espécie (Silva e Costa, 2005).

Por tratar-se de uma espécie de importância considerável, uma vez que é encontrada por todos os biomas do país, seu couro pode ser utilizado na produção de acessórios, como sapatos e bolsas, e sua carne é muito apreciada (FARIA, 2005) destaca-se a falta de trabalhos relacionados à morfologia destes animais.

Moro e Abdala (2004) descreveram a musculatura flexora e extensora dos membros torácicos e pélvicos do Polychrus acutirostris (lagarto cego). Segundo os autores, estas musculaturas estão relacionadas com os movimentos finos. Podemos considerar que movimentos especializados como estes, implicam em estruturas anatômicas particulares. Estes animais ao se deslocaram necessitam que os membros realizem movimentos individuais, especialmente os dedos, para se apoiarem e se locomoverem, alternando de um digito para outro.

O principal objetivo deste trabalho é contribuir com a descrição da miologia do peitoral e dos membros do lagarto T. merianae, pois, como já citado por diversos autores como Hildebrand (1995); Dyce et al. (2004) e Getty (2008), o conhecimento da anatomia tem importâncias e aplicações em diversas áreas dentro da biologia, contribuindo de maneira substancial para as áreas da saúde humana e da tecnologia.

\section{Material e Métodos}

Para o presente estudo utilizamos três animais (teiús) atropelados provenientes de doação junto ao campus da Faculdade de Zootecnica e Engenharia de Alimentos da Universidade de São Paulo, campus Pirassununga, São Paulo, Brasil. Os lagartos foram fixados em formol 10\%. Os animais foram dissecados, seguindo técnicas tradicionais para este tipo de estudo, a derme foi retirada e em seguida a musculatura dissecada com o auxilio de bisturi, pinça anatômica e tesoura fina romba. A análise macroscópica realizada com acurácia e ricamente foto documentada.

\section{Resultados e Discussão}

Abdala e Diogo (2010) descreveram a anatomia comparada, homologia e evolução da musculatura peitoral e membros anteriores dos tetrápodes com especial atenção aos anfíbios e répteis. A musculatura peitoral, dos membros torácicos destas espécies segue uma conformação adquirida na história evolutiva dos tetrápodes.

Os músculos do lagarto Teiú apresentam cor semelhante à observada em crocodilianos, aves e algumas espécies de peixes, sendo de cor clara, aspecto firme e bem delimitada (Figura 1).

O número de músculos encontrados nos répteis é bem diferente dos já descritos em mamíferos e aves, uma vez que esta classe possui poucos grupos musculares na formação dos membros, este resultado pode ser observado nas descrições de Hildebrand (1995). O autor descreve sobre a classe dos reptilianos em seu livro "Análise da estrutura dos vertebrados".

Assim como nos anfíbios e nos répteis, as camadas; dorsal e ventral dos extensores têm a mesma estrutura básica, sendo os dois compostos, superficialmente, por três complexos musculares: o "extensor/flexor da ulna", o "extensor/flexor do radio" e o "extensor/flexor do digital comum/longo". Esta divisão corresponde à observação realizada no Teiú. Esses complexos musculares normalmente têm origem no úmero e inserção na porção distal do radio, na porção distal da ulna e nos ossos do carpo, metacarpo e falanges, respectivamente. Esses seis 
FIGURA 1: Lagarto Teiú (A), destaque para o aspecto da musculatura sendo de cor clara, aspecto firme e bem delimitada (B, C, D).

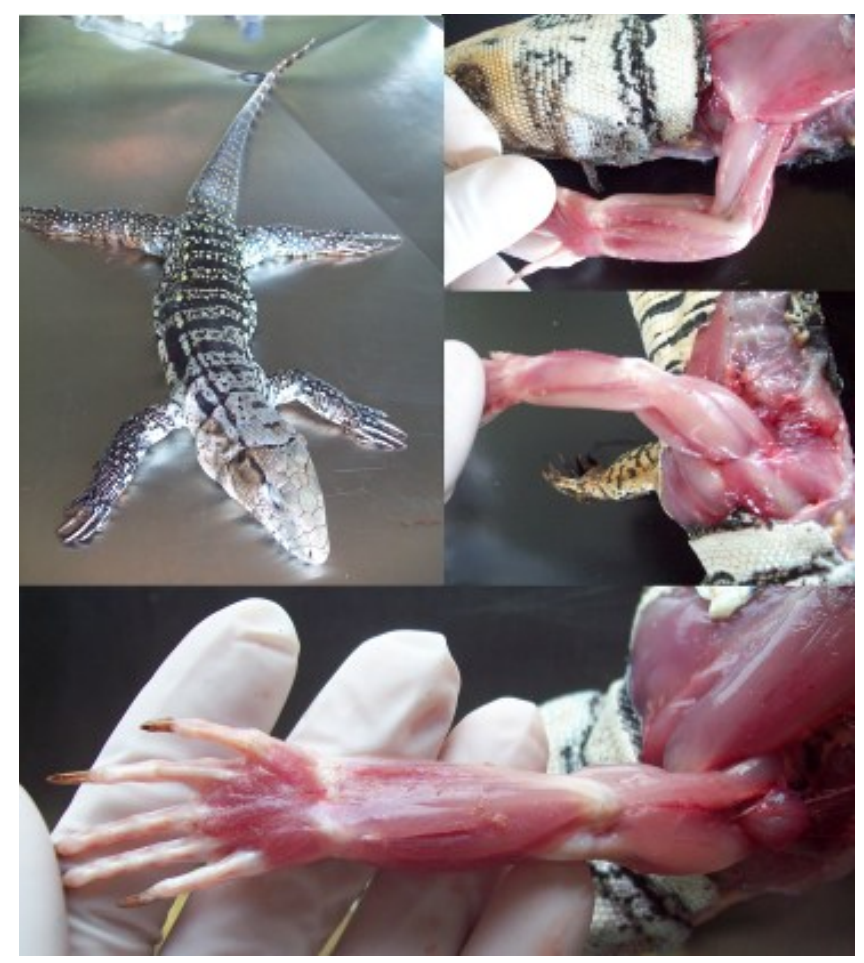

complexos musculares estão presentes na maioria das espécies de anfíbios e répteis existentes, que possuem membros (ABDALA; DIOGO, 2010).

No teiú, a musculatura do membro torácico é composta pelos músculos tríceps, extensores dos carpos e dígitos, na região ventral foram observados os músculos bíceps, coracobraquial, o músculo braquial e os flexores dos dígitos do carpo (Figura 2).

Os músculos interdigitais são um conjunto de quatro músculos, cada um dos quais se originam na lateral da extremidade proximal do metacarpo do digito seguinte. São cruzados entre os metacarpianos, bem visíveis e são inseridos na face lateral da extremidade distal do metacarpo do digito correspondente ao nome (MORO; ABDALA, 2004).

Nossos achados foram semelhantes aos descritos por Moro e Abdala (2004) nos Polychrus acutirostris. Os músculos extensores e dígitos do carpo relacionam a região proximal do membro toracico até a região distal, no conjunto de músculos extensores estão presentes: Músculo Extensor digitorum longus, que se origina na

FIGURA 2: Musculatura do membro torácico do Teiú.

m. Extensor digital curto IV

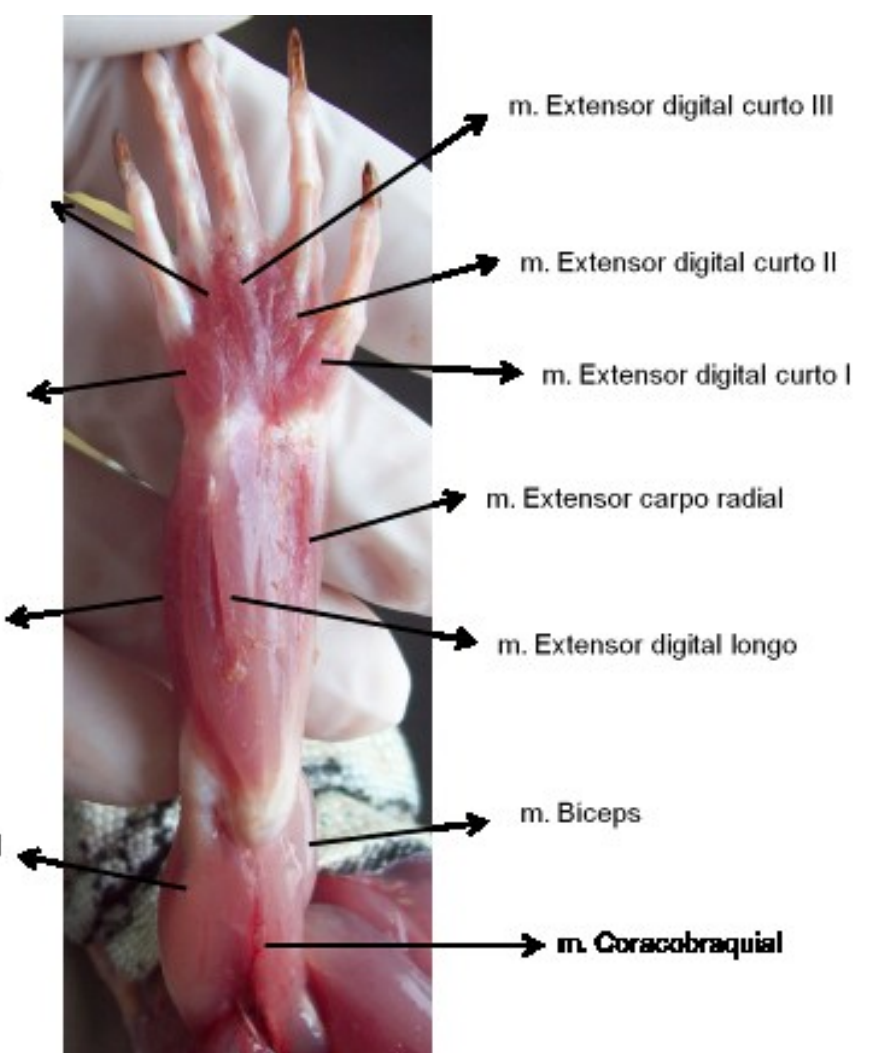


região ectepicondilar da cabeça do úmero distal por meio de uma folha fascial compartilhada com o músculo extensor radial do carpo. Esta folha é a mais superficial tendinosa.

O primeiro terço do músculo do corpo está intimamente relacionado com o músculo extensor radial do carpo. O Abductor longus pollici, que se origina na superfície externa do grande dorsal distal da ulna, triangular e mais largo na origem. Fica em torno da articulação dorsal do carpo, como uma pulseira, é introduzido através de um tendão curto mais visível na extremidade lateral externa distal do metacarpo I (MORO; ABDALA, 2004).

O Extensor carpi ulnaris, que se origina na cabeça distal do úmero por um tendão curto, se estende sobre a superfície do músculo ao longo de aproximadamente um quinto de seu comprimento total que são inseridos na aponeurose comum com o músculo flexor ulnar do carpo, enquanto a outra parte (a mais interna) é inserida de maneira carnuda no dois terços distais da ulna (MORO; ABDALA, 2004).

O Extensor carpi radialis se origina de um tendão curto, largo e muito visível no lado exterior da extremidade distal do úmero e se insere na face fora da extremidade distal do rádio. Os Extensores digitorum brevis, que são um conjunto de cinco músculos que originam-se da ulna. Os músculos vão para os dedos e são inseridos sobre a extremidade distal do metacarpo correspondente a cada dedo. Os Dorsometacarpales são um conjunto de músculos que ficam entre o carpo e cada um dos digitos e são inseridos na face dorsal da base das falanges e por fim o Abductor digitorum que tem origem pisiforme e se insere na face lateral da extremidade distal do metacarpo V (MORO; ABDALA, 2004).

Os membros torácicos do teiú ainda apresentam um conjunto de quatro músculos, cada um dos quais se origina na lateral da extremidade proximal do digito.

A musculatura peitoral dos répteis apresenta seis músculos derivados da musculatura axial: o serratil anterior, 'romboíde', levantador da escápula, opercular, esternocoracóide e costocoracóide. São músculos intrínsecos da região proximal do membro torácico, que possuem formato de leque e vão do esterno, clavícula e/ou estruturas adjacentes para o úmero e/ou escápula. Estes resultados foram semelhantes aos encontrados por Abdala e Diogo, (2010).

O músculo coracobraquial origina-se a partir do músculo peitoral (esternocoracóide) e insere-se na articulação flexora do carpo, assim como o músculo braquial, porém origina-se no costocoracóide do peitoral (ABDALA; DIOGO, 2010) (Figura 3).

O bíceps localiza-se acima do coracobraquial originando-se no levantador da escápula do peitoral com inserção no inicio dos flexores do carpo, estes se originam na articulação flexora braquial e inserem-se na articulação dos dígitos do carpo (ABDALA e DIOGO, 2010).

Já a musculatura do membro pélvico (Figura 4) é formada pelos músculos ambiens, pubotibial, puboisquiotibial, puboisquiofemoral, adutor do fêmur, flexor tibial interno, flexor tibial externo, femorotibial, gastrocnêmio, tibial anterior e flexor longo dos dígitos.

O músculo tibial cranial é o músculo do membro pélvico que se estende lateralmente à borda cranial da tíbia, originando-se na superfície lateral da tíbia e inserindo-se na superfície plantar da base do metatarso.

Apesar da escassez de trabalhos sobre a anatomia da espécie aqui descrita, pudemos comparar os resultados obtidos com autores que estudaram animais da mesma classe Reptilia. Com isso concluímos que nossos resultados macroscópicos assemelham-se aos já descritos pelos pesquisadores Hildebrand (1995); Moro e Abdala, (2004); Abdala e Diogo (2010). 
FIGURA 3: Musculatura Peitoral e de região proximal do membro torácico.

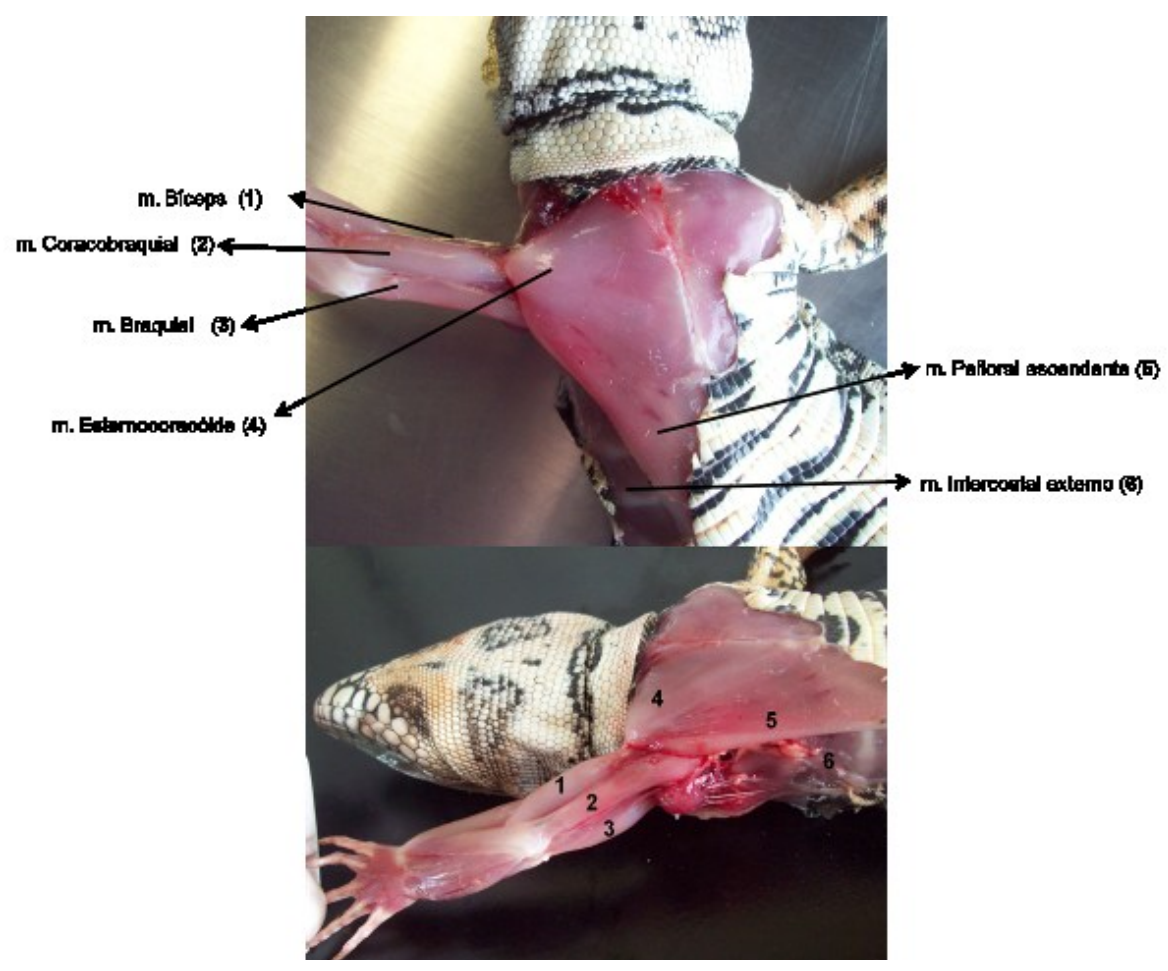

FIGURA 4: Musculatura do membro pélvico do lagarto teiú.

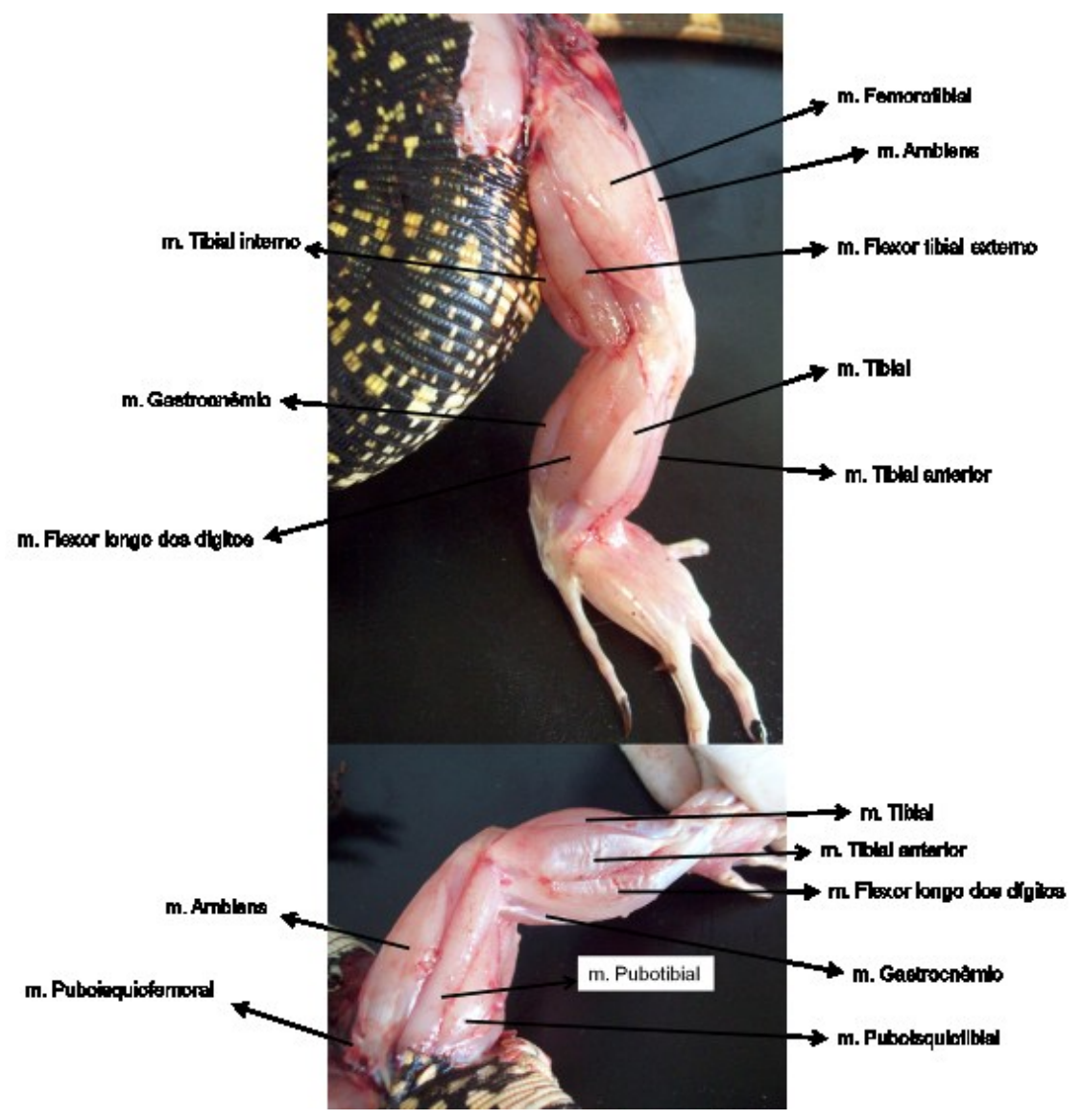




\section{Agradecimentos}

À FZEA/USP pelo incentivo à produção científica e à FAPESP por permitir a dedicação à pesquisa em período integral do autor principal.

\section{Referências}

ABDALA, V.; DIOGO, R. Comparative anatomy, homologies and evolution of the pectoral and forelimb musculature of tetrapods with special attention to extant limbed amphibians and reptiles. Journal of Anatomy, Maiden, v. 217, p. 536-573, 2010.

ARGÔLO FILHO, R. C. Identificação, sorotipagem e diferenciação pela PCR-DGGE de sorotipos de Salmonella isolados de teiús criados em cativeiro. 2007. 96 f. Dissertação (Mestrado em Genética e Biologia Molecular) - Universidade Estadual de Santa Cruz, Ilhéus. 2007.

ÁVILA-PIRES, T. S. C. Lizards of Brazilian Amazonia (Reptilia: Squamata). Zoologische Verhandelingen, Leiden, v. 299, p. 1-706, 1995.

CASTRO, E. R.; GALETTI, M. Frugivoria e dispersão de sementes pelo lagarto teiú Tupinambis merianae (Reptilia: Teiidae). Papéis Avulsos de Zoologia, São Paulo, v. 44, n. 6, p. 91-97, 2004.

COLLI, G. R. Tupinambis merianae. 2005. Disponível em: $<$ http:// www.unb.br/ib/zoo/grcolli/guia/tmerianae.htm>. Acesso em: 10 out. 2009.

COSTA, H. C.; MOURA, M. R. Teiú (Tupinambis merianae). 2011. Disponível em <www.museudezoologia.ufv.br>. Acesso em: 30 set. 2009.

DYCE, K. M.; SACK, W. O.; WENSING, C. J. G. Tratado de Anatomia Veterinária. 3. ed. Rio de Janeiro: Elsevier, 2004. 813 p.

FARIA, T. A. Análise comportamental da preferência e consumo de rações comerciais em teiús Tupinambis merianae (DURMÉRIL e BIBRON, 1839) (Squamata, Teiidae) mantidos em cativeiro. 2005. 70 f. Dissertação (Mestrado em Zoologia) Universidade Estadual de Santa Cruz, Ilhéus. 2005.
FRANCISCO, L. R. Répteis do Brasil: manutenção em cativeiro. São José dos Pinhais: Editora Amaro, 1997. 207 p.

GETTY, R. Anatomia dos animais domésticos. 5. ed. Rio de Janeiro: Editora Guanabara Koogan, 2008. 2000 p.

HADDAD JR., V.; DUARTE, M. R.; GARRONE NETO, D. Tegu (Teiu) Bite: report of human injury caused by a Teiidae lizard. Wilderness and Environmental Medicine, Salt Lake City, v. 19, p. 111-113, 2008

HILDEBRAND, M. Análise da estrutura dos vertebrados. São Paulo: Editora Atheneu, 1995. 650 p.

MAFFEI, F.; DOMINGUES, M. T. C.; SILVA, H. F. B. Genética e Hematologia de lagartos do gênero Tupinambis (Sauria: Teiidae). Salusvita, Bauru, v. 26, n. 3, p. 69-78, 2007.

MORO, S.; ABDALA, V. Análisis descriptivo de la miologia flexora y extensora del miembro anterior de Polychrus acutirostris (Squamata, Polychrotidae). Papéis Avulsos de Zoologia, São Paulo, v. 44, p. 81-89, 2004.

PÉRES JR., A. K. Sistemática e conservação de lagartos do gênero Tupinambis (Squamata, Teiidae). 2003. 192 f. Tese (Doutorado em Biologia Animal) - Universidade de Brasília, Brasília. 2003.

SILVA, G. M.; COSTA, L. C. Observação oportunística de corte e cópula de Tupinambis merianae (Dumeril e Bilbron,1839) (Squamata, Teiidae). In: CONGRESSO BRASILEIRO DE ZOOLOGIA, XXV, 2004, Brasília. Anais... Brasília: SBZ, 2004. Vol. 25, p. 414.

SILVA, G. M.; COSTA, L. C. M. Descrição dos padrões motores do Tupinambis merianae (Duméril e Bilbron, 1839) (Squamata, Teiidae) e do Caiman crocodilus yacare (Daudin, 1802) (Crocodylia, Alligatoridae) em cativeiro no Zoológico Municipal de Curitiba, Paraná, Brasil. Revista Brasileira de Zoociências, Juiz de Fora, v. 7, n. 1, p. 93-109, 2005.

WINCK, G. R. História Natural de Tupinambis merianae (Squamata, Teiidae) na Estação Ecológica do Taim, sul do Brasil. 2007. 57 f. Dissertação (Mestrado em Ciências Biológicas) - Universidade Federal de Santa Maria, Santa Maria. 2007. 